\title{
Supporting Information \\ Shear-dependent Structures of Flocculated Micro/Nanofibrillated \\ Cellulose (MNFC) in Aqueous Suspensions
}

Emily G. Facchine, ${ }^{1}$ Richard J. Spontak, ${ }^{1,2}$ Orlando J. Rojas ${ }^{1,3^{*}}$ and Saad A. Khan ${ }^{1 *}$

Departments of ${ }^{1}$ Chemical \& Biomolecular Engineering and ${ }^{2}$ Materials Science \&

Engineering, North Carolina State University, Raleigh, NC 27695, USA; ${ }^{3}$ Department of

Chemical \& Biological Engineering, The University of British Columbia, Vancouver BC

Canada V6T $1 Z$ 

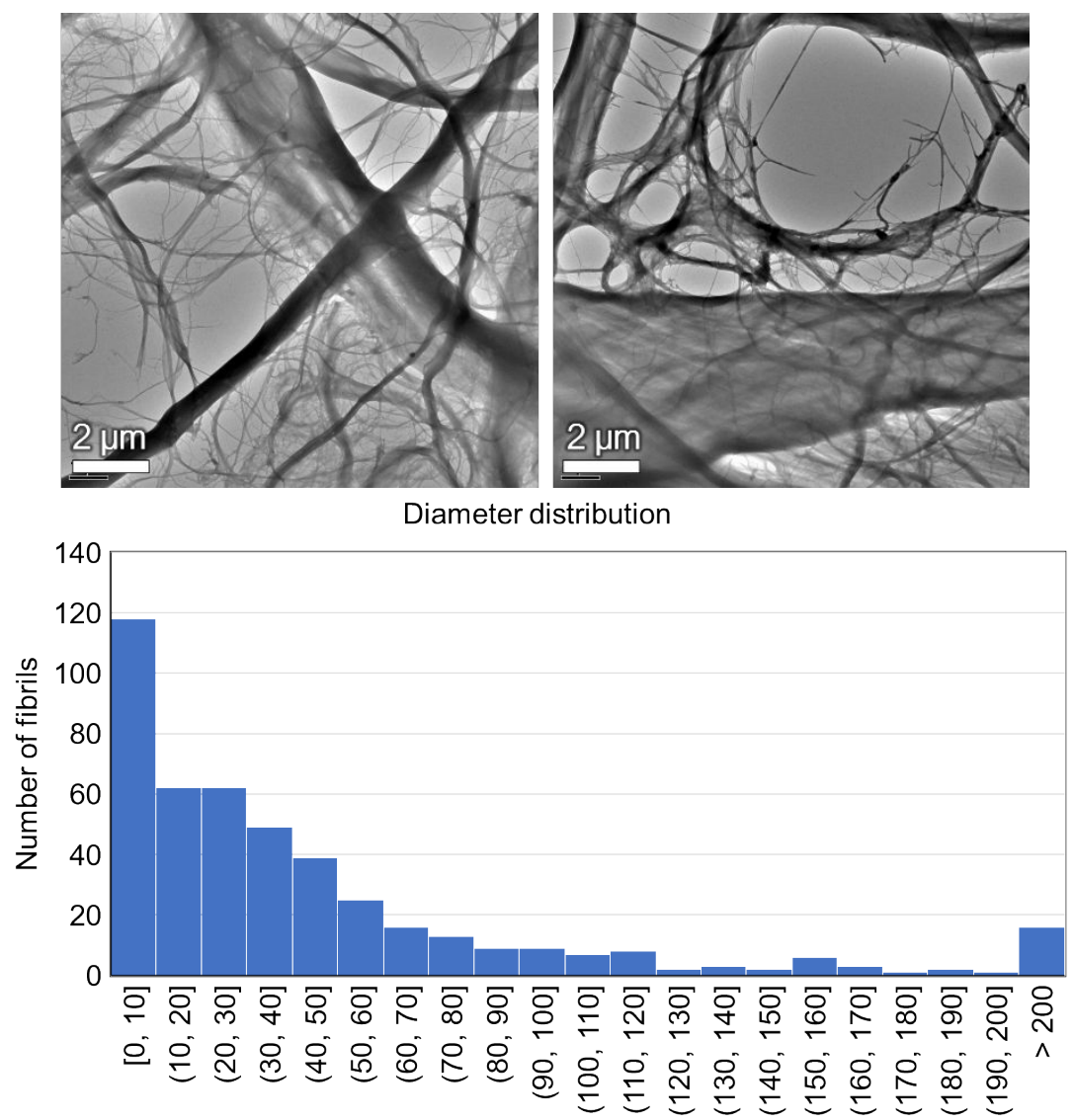

Fibril diameter (nm)

Figure S1. Fibrillar diameters (top) as measured from transmission electron microscopy

images (bottom). 


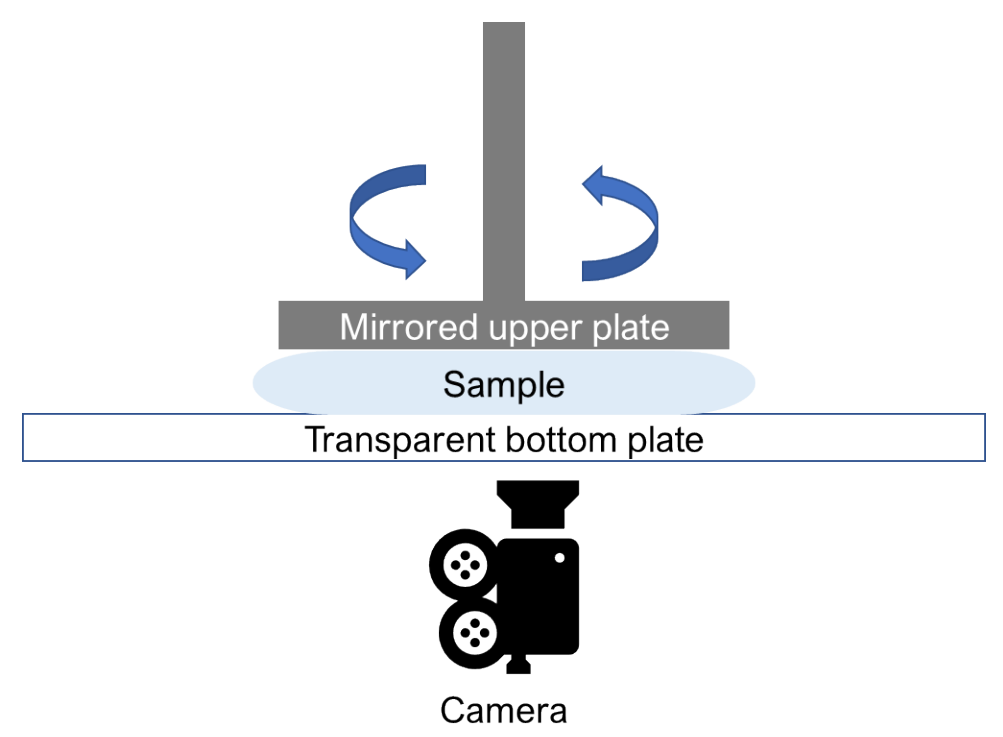

Figure S2. Schematic diagram of the rheo-optical imaging setup.
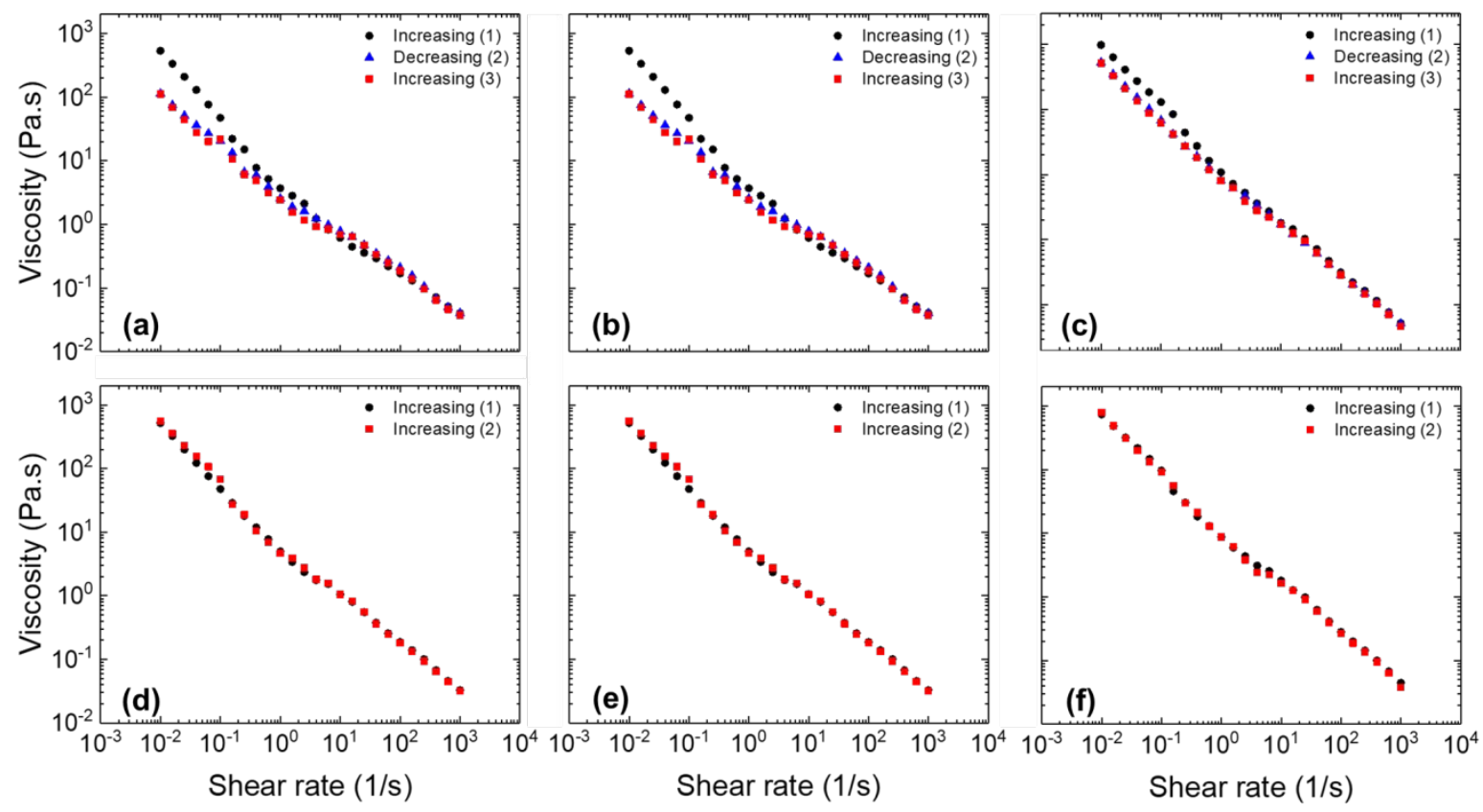
Figure S3. Slow-quench (a-c) vs. fast-quench (d-f) test sequences for MNFC suspensions differing in composition (in wt\%): (a,d) 2, (b,e) 2.5, (c,f) $3.1 \%(c, f)$. The symbols are described in the legends.

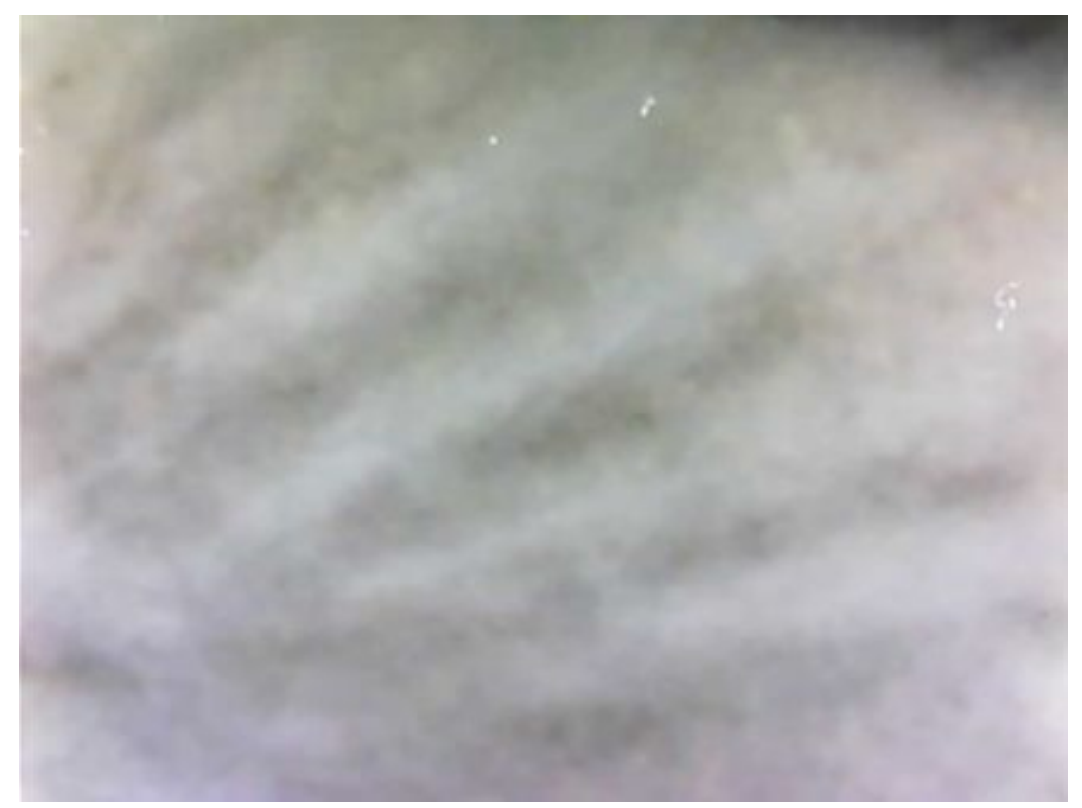

Figure S4. Rheometer image from intermediate oscillatory stress (10 Pa)

Fibril size analysis

The difficulty of accurately measuring lengths of MNFC has been documented, ${ }^{1,2}$ but an approximation can be reached by using the relationship between intrinsic viscosity and aspect ratio. The manufacturer ${ }^{3}$ lists the fiber dimensions for MNFC as follows: "Fiber 
dimensions: nominal fiber width of $50 \mathrm{~nm}$, lengths of up to several hundred microns." By applying the Simha equation ${ }^{4}$ using calculated intrinsic viscosity and the density of fibrils as provided by the manufacturer $\left(1.5 \mathrm{~g} / \mathrm{cm}^{3}\right)$, we predict an aspect ratio of 189 .

Iwamoto et al. ${ }^{5}$ studied the use of the Simha equation to estimate aspect ratios of TEMPO-CNFs and found that it resulted in an underprediction, with actual aspect ratios roughly twice the estimated value. We therefore take the prediction of 189 as an approximation of the minimum aspect ratio and consider that a more reasonable estimate is obtained by doubling this value $(a=378)$. With this updated estimate, and TEM measured diameters in the range of $5-200 \mathrm{~nm}$, we arrive at lengths of individual fibrils in the range of 2-75 $\mu \mathrm{m}$. When considering the extensive entanglement and aggregation at play in the system, the manufacturer's estimate of "several hundreds of microns" remains valid in practice.

Generally, particle sizes $>1 \mu \mathrm{M}$ are not expected to show remarkable Brownian motion, ${ }^{6}$ and in the case of MNFC the largest fibril dimension is almost always in excess of that limit, sometimes by an order of magnitude or more. While some systems of cellulose 
nanomaterials may exhibit Brownian effects in the limits of very dilute suspensions $(\Phi \ll<$ $\left.a^{-2}\right),{ }^{7,8}$ the samples discussed here are not considered dilute and are expected to have substantial contributions of hydrodynamic forces $(\mathrm{Pe}>1) .^{9}$

We refer to an analysis presented by Tao et al. for long thin rods, ${ }^{10}$ and we calculate rotational and translational diffusion constants to be $D_{r}=7.67^{*} 10^{-4} \mathrm{~s}^{-1}$ and $D_{t}=1.17^{*} 10^{-}$ ${ }^{13} \mathrm{~m}^{2} \mathrm{~s}^{-1}$. This calculation assumes a fibril length of $38 \mu \mathrm{m}$ and diameter of $10 \mathrm{~nm}$.

Using a fibril length of $38 \mu \mathrm{m}$ and diameter of $10 \mathrm{~nm}$, cellulose density $1.5 \mathrm{~g} / \mathrm{cm}^{3}$, a 1.0 wt. \% suspension is calculated to have a number density of $1.76 \times 10^{12} \mathrm{~mL}^{-1}$.

We note that these calculations are subject to certain limitations, such as approximation of MNFC particles as long thin rigid rods, and these values should be taken only as relative measures for comparison and not necessarily as definitive quantifications. 


\section{References}

(1) Shinoda, R.; Saito, T.; Okita, Y.; Isogai, A. Relationship between Length and Degree of Polymerization of TEMPO-Oxidized Cellulose Nanofibrils. Biomacromolecules 2012, 13(3), 842-849. https://doi.org/10.1021/bm2017542.

(2) Li, Q.; Renneckar, S. Molecularly Thin Nanoparticles from Cellulose: Isolation of Sub-Microfibrillar Structures. Cellulose 2009, $16 \quad$ (6), 1025-1032. https://doi.org/10.1007/s10570-009-9329-6.

(3) Nanocellulose Data Sheets - The Process Development Center - University of Maine. The Process Development Center. https://umaine.edu/pdc/nanocellulose/nanocellulose-spec-sheets-and-safety-datasheets/ (Accessed June 2, 2020)

(4) Simha, R. The Influence of Brownian Movement on the Viscosity of Solutions. J. Phys. Chem. 1940, 44 (1), 25-34. https://doi.org/10.1021/j150397a004. 
(5) Iwamoto, S.; Lee, S.-H.; Endo, T. Relationship between Aspect Ratio and Suspension Viscosity of Wood Cellulose Nanofibers. Polym. J. 2014, 46 (1), 73-76. https://doi.org/10.1038/pj.2013.64.

(6) Chapter 6 - Physics of Electrorheological Fluids. In Studies in Interface Science; Hao, T., Ed.; Electrorheological Fluids; Elsevier, 2005; Vol. 22, pp 235-340. https://doi.org/10.1016/S1383-7303(05)80021-3.

(7) Johan Foster, E.; J. Moon, R.; P. Agarwal, U.; J. Bortner, M.; Bras, J.; CamareroEspinosa, S.; J. Chan, K.; D. Clift, M. J.; D. Cranston, E.; J. Eichhorn, S.; M. Fox, D.; Y. Hamad, W.; Heux, L.; Jean, B.; Korey, M.; Nieh, W.; J. Ong, K.; S. Reid, M.; Renneckar, S.; Roberts, R.; Anne Shatkin, J.; Simonsen, J.; Stinson-Bagby, K.; Wanasekara, N.; Youngblood, J. Current Characterization Methods for Cellulose Nanomaterials. Chem. Soc. Rev. 2018, 47 (8), 2609-2679. https://doi.org/10.1039/C6CS00895J.

(8) Bröckel, U.; Meier, W.; Wagner, G. Product Design and Engineering: Formulation of Gels and Pastes; John Wiley \& Sons, 2013. 
(9) Hubbe, M. A.; Tayeb, P.; Joyce, M.; Tyagi, P.; Kehoe, M.; Dimic-Misic, K.; Pal, L. Rheology of Nanocellulose-Rich Aqueous Suspensions: A Review. BioResources 2017, $12(4), 9556-9661$.

(10) Tao, Y.-G.; den Otter, W. K.; Padding, J. T.; Dhont, J. K. G.; Briels, W. J. Brownian Dynamics Simulations of the Self- and Collective Rotational Diffusion Coefficients of Rigid Long Thin Rods. J. Chem. Phys. 2005, $122 \quad$ (24), 244903. https://doi.org/10.1063/1.1940031. 